\title{
Plantas medicinais e suas possíveis contribuições: um estudo bibliográfico em dissertações e teses presentes na BDTD no período 2015-2020
}

\author{
Medicinal plants and their possible contributions: a bibliographical study in dissertations and
} theses present in BDTD in the period 2015-2020

Plantas medicinales y sus posibles aportes: un estudio bibliográfico en disertaciones y tesis presentes en el BDTD en el período 2015-2020

\section{Resumo}

As plantas medicinais se apresentam como um importante lócus investigativo. Pensando nisso, o presente artigo buscou mapear e analisar teses e dissertações presentes na Biblioteca Digital de Teses e Dissertações (BDTD), no período de 2015 a 2020 que inserem tendências, práticas e atividades voltadas a plantas medicinais, bem como sua relevância para o meio socioeducacional. Por meio de um levantamento bibliográfico, encontrou-se um total de 151 pesquisas, sendo 112 dissertações e 39 teses. A forma de seleção destes trabalhos se deu por meio do termo "plantas medicinais" presentes nos títulos dos trabalhos mapeados. Como metodologia adotada, utilizou-se uma análise bibliográfica, com a criação dos seguintes descritores: ano de publicação, instituições e regiões brasileiras, bem como optou-se pela criação de três categorias a priori: Categoria I: Tendências no uso de plantas medicinais; Categoria II: Contribuições no uso de plantas medicinais e Categoria III: Práticas no uso de plantas medicinais. Para a análise dos dados, utilizou-se a Análise Textual Discursiva. Por meio deste levantamento pôde-se perceber que a região nordeste brasileira é que mais desenvolve pesquisas na área de plantas medicinais, contribuindo com a divulgação científica desta temática.

Palavras-chave: Plantas medicinais; Práticas; Contribuições; Tendências.

\begin{abstract}
Medicinal plants present themselves as an important investigative locus. With this in mind, this article sought to map and analyze theses and dissertations present in the Digital Library of Theses and Dissertations (BDTD), from 2015 to 2020 that include trends, practices and activities aimed at medicinal plants, as well as their relevance to the environment socio-educational. Through a bibliographical survey, a total of 151 researches were found, being 112 dissertations and 39 theses. The form of selection of these works was through the term "medicinal plants" present in the titles of the mapped works. As adopted methodology, a bibliographic analysis was used, with the creation of the following descriptors: year of publication, institutions and Brazilian regions, as well as the creation of three a priori categories: Category I: Trends in the use of medicinal plants; Category II: Contributions in the use of medicinal plants and Category III: Practices in the use of medicinal plants. For data analysis, Discursive Textual Analysis was used. Through this survey, it could be seen that the Brazilian northeast region is the one that develops the most research in the area of medicinal plants, contributing to the scientific dissemination of this theme.
\end{abstract}

Keywords: Medicinal plants; Practices; Contributions; Tendencies.

\section{Resumen}

Las plantas medicinales se presentan como un importante lugar de investigación. Con esto en mente, este artículo buscó mapear y analizar las tesis y disertaciones presentes en la Biblioteca Digital de Tesis y Disertaciones (BDTD), en el período de 2015 a 2020, que incluyen tendencias, prácticas y actividades dirigidas a las plantas medicinales, así como como su relevancia para el entorno socioeducativo. Mediante un relevamiento bibliográfico se encontraron un total de 151 investigaciones, siendo 112 disertaciones y 39 tesis. La forma de selección de estas obras fue a través del término "plantas medicinales" presente en los títulos de las obras cartografiadas. Como metodología adoptada, se utilizó un análisis bibliográfico, con la creación de los siguientes descriptores: año de publicación, instituciones y 
regiones brasileñas, así como la creación de tres categorías a priori: Categoría I: Tendencias en el uso de plantas medicinales; Categoría II: Contribuciones en el uso de plantas medicinales y Categoría III: Prácticas en el uso de plantas medicinales. Para el análisis de los datos se utilizó el Análisis Textual Discursivo. A través de esta encuesta, se pudo constatar que la región noreste brasileño es la que más investigaciones desarrolla en el área de plantas medicinales, contribuyendo a la divulgación científica de este tema.

Palabras clave: Plantas medicinales; Prácticas; Contribuciones; Tendencias.

\section{Introdução}

As plantas são seres vivos que acompanharam o processo evolutivo na vida do Planeta. Ao longo de milhares de ano, por meio de mutações, novos mecanismos evolutivos e adaptativos surgiram, contemplando a atual variedade morfofisiológica das plantas. Nesse contexto, por meio de pesquisas científicas, ocorre a busca por respostas aos problemas que estão presentes na sociedade. De forma contundente, a evolução humana apresentou/apresenta diversas enfermidades e a pesquisa cientifica tenta buscar soluções para mitigar riscos aos problemas sociais, utilizando as plantas medicinais.

As plantas medicinais se apresentam como um importante campo investigativo das pesquisas cientificas, sendo que novas descobertas impulsionam tendências, práticas e conhecimentos científicos voltadas aos saberes sociais, bem como ao uso farmacológico. Por meio de novas inovações pode-se encontrar novas curas ao tratamento de doenças, como diabetes, problemas respiratórios, circulatórias, cardiovasculares, cujo consumo de plantas medicinais podem ocasionar reações ao organismo, bem como o alívio de dores ou sensação de calma, resultando no tratamento de enfermidades e na prevenção de doenças.

As plantas medicinais são corriqueiramente utilizadas por diferentes culturas, visando o combate e controle de doenças e enfermidades. O uso das plantas na medicina provém deste os tempos das primeiras civilizações e, hoje, se apresenta como um importante campo científico, com vistas a contribuir com o processo de socialização dos diversos saberes presentes no meio sociocultural. Sabe-se que as plantas medicinais vêm ganhando espaço no meio acadêmico, seja pelas suas características terapêuticas, seja pela sua influência nos saberes locais/socias. Nesse mesmo sentido, deve-se haver uma interlocução entre a academia e a sociedade na busca por um diálogo constante, com vistas a socializar estes conhecimentos e potencializar novas descobertas. Da mesma forma, é plausível destacar que as plantas medicinais contribuem na prevenção de infecções cotidianas da população. Entretanto, seu uso indiscriminado e sem cientificidade pode ocasionar o surgimento de mutações em nível celular, podendo ocorrer o surgimento de doenças e problemas graves que causam mal à saúde.

A presente investigação contempla o Projeto de Pesquisa intitulado "Análise anatômica de plantas medicinais", vinculado ao Instituto Federal Farroupilha. Cabe dizer que o projeto tem o objetivo de estudar a anatomia e histoquímica de plantas medicinais. Imerso neste projeto, está o subprojeto "Plantas medicinais utilizadas pelas mulheres da Comunidade de São João do Barro Preto do Município de Júlio de Castilhos, Rio Grande do Sul, Brasil” que está vinculado ao Instituto Federal Farroupilha do Campus Júlio de Castilhos. Este subprojeto tem a incumbência de compreender, por meio do diálogo, as plantas medicinais que estão sendo utilizadas pelas mulheres que residem nesta localidade e suas contribuições para o meio sociocultural.

Destarte, devido a pandemia causada pelo novo Coronavírus, o qual atinge toda população mundial, a presente pesquisa não pode ser desenvolvida de forma presencial, em laboratório. Entretanto, optou-se por estudos em bases bibliográficas, a fim de discutir as novas pesquisas relacionadas as plantas medicinais, principalmente as que estão presentes em teses e dissertações. Diante disso, foi realizada uma revisão bibliográfica na Biblioteca Digital de Teses e Dissertações (BDTD), a qual se apresenta como um banco de dados que visa o armazenamento, tanto de dissertações quanto teses, contribuindo com a divulgação cientifica nas diferentes áreas do conhecimento. Pensando na importância em conhecer as pesquisas voltadas a temática plantas medicinais o presente artigo buscou mapear e analisar teses e dissertações presentes na BDTD no período de 2015 a 2020 que inserem tendências, práticas e atividades voltadas a plantas medicinais, bem como sua 
relevância para o meio socioeducacional.

\section{Referencial Teórico}

O uso de plantas medicinais utilizadas pelo homem é uma temática que necessita ser discutida constantemente. Nobrega (2017, p. 11) afirma que em diversas comunidades rurais há o predomínio no uso de plantas medicinais devido ao hábito tradicional das pessoas buscarem a cura de enfermidades nos recursos existentes em seu ambiente, em virtude da pouca disponibilidade de recursos financeiros para deslocamento até a cidade mais próxima, bem como isso se dá ao elevado custo de consultas médicas e a compra de medicamentos em farmácias convencionais. Segundo a autora remédios da mata são mais saudáveis e não têm venenos, considerados por suas funções curativas tão eficazes quanto os de farmácia.

Pensando no uso de plantas medicinais para o tratamento de doenças respiratórias, Gomes (2002) afirma que as doenças respiratórias presentes estão relacionadas a agressões ambientais e estas alterações podem se diferenciar de acordo com o nível de exposição aguda. Nesse sentido, pode- dizer que o surgimento de problemas à saúde humana se dá ao fato dos problemas ambientais e seus reflexos posteriores. Sendo assim, deve-se haver um cuidado para/com o ambiente, com vistas a uma qualidade de vida.

Rahman e Kang (2009) discutem os riscos que microrganismos patogênicos venham a desenvolver resistência aos óleos essenciais e extratos vegetais. Para os pesquisadores os riscos são muito baixos, uma vez que estes produtos contêm uma mistura de substâncias antimicrobianas, que atuam através de diversos mecanismos. Esta é uma característica benéfica e vantajosa dos produtos derivados de plantas sobre outros agentes antimicrobianos e pode vir a aumentar a segurança alimentar e a vida de prateleira dos alimentos. Nesse contexto, pode-se verificar que as plantas podem ser utilizadas de diferentes formas, a fim de contribuir com a qualidade de vida e bem-estar do homem.

O estudo de Araújo (2009) envolvendo plantas medicinais discute o processo de produção e reprodução de múltiplos saberes e práticas, originados de diversas formas culturais e que resulta da organização social e produtiva de comunidades tradicionais. O conhecimento sobre a utilização das plantas medicinais é de extrema importância para os estudos etnobotânicos, pois os remédios caseiros servem como alternativa de cura e/ou melhora de sintomas de doenças, na ausência de outras formas de tratamento ou falta de recursos para o tratamento.

Na visão de Rudder (2002), plantas medicinais são aquelas que possuem uma ou mais propriedades reconhecidas de cura, prevenção, diagnóstico ou tratamento sintomático de doenças, usando-se órgãos ou partes das plantas que apresentam atividade terapêutica, devido à presença de um determinado princípio ativo. Segundo o autor, as plantas medicinais podem ser classificadas por categorias, de acordo com sua ação sobre o organismo: estimulantes, calmantes, emolientes, fortificantes, de ação coagulante, diuréticas, sudoríferas, hipotensoras, de função reguladora intestinal, colagogas, depurativas, remineralizastes e reconstituintes.

Gill (2009) aborda uma questão relevante a ser discutida acerca dos saberes locais e tradicionais envolvendo homens e mulheres. A conclusão que se chegou é que não são somente as mulheres que atuam no benzimento envolvendo plantas medicinais. Alguns homens também se dedicam a reza, sobretudo, para a manutenção da atividade produtiva, ao benzer animais, carros, tratores, por exemplo, mas são muitos os que também enfocam o cuidado das pessoas. Nesta perspectiva, pode-se dizer que o gênero não interfere no benzimento, visto que é cultural e envolve saberes locais e tradicionais.

A pesquisa de Nery (2006) vem ao encontro dos estudos de Gil (2009) quando discute que o benzedor homem é procurado em especial para rezar e que parte das benzeduras servem para curar doenças, muitas para o quebranto e outras para engasgo, dor de pontada, cobreiro, dor dente e muitas outras. Sendo que algumas orações não podem ser reveladas, como aquelas rezadas contra os inimigos ou para fechar o corpo, pois os benzedores temem que, revelando o segredo, elas possam perder o encanto. A simplicidade dos versos emoldura a expressão da fé, oração que é poesia e é palavra evocatória de cura e 
proteção.

Bragança (1996) também discute os saberes locais e tradicionais ao discutir que os indígenas que habitavam o solo brasileiro faziam o uso de ervas medicinais em rituais e na terapêutica. Da mesma forma tinham uma concepção mística da origem de todas as doenças sem causa externa identificável (ferimentos, fraturas, envenenamentos, entre outros). Acreditando em fatores sobrenaturais, os pajés associavam o uso de plantas aos rituais de magia e seus tratamentos eram, assim, transmitidos oralmente de uma geração à outra.

\section{Metodologia}

Em se tratando da metodologia utilizada, pode-se dizer que ocorreu uma pesquisa bibliográfica na base de dados da Biblioteca Digital de Teses e Dissertações (BDTD). Gil (2002) comenta que toda a pesquisa científica necessita de estudos bibliográficos, visando mapear os trabalhos que abordam uma determinada temática de interesse do pesquisador. Inicialmente ocorreu uma busca por meio da seleção das teses e dissertações utilizando o termo 'plantas medicinais' presentes nos títulos. Por meio deste mapeamento inicial foi possível encontrar um total de 151 trabalhos, cujo período analisado foi de 2015 até 2020.

Do total de pesquisas encontradas envolvendo a terminologia plantas medicinais, 112 são dissertações e 39 teses, as quais compreendem o corpus deste levantamento. Para a análise dos dados, foram criados os seguintes descritores: ano de publicação, Programas de Pós-graduação, Universidades, bem como regiões brasileiras que estão pesquisando a temática plantas medicinais. Para analisar os trabalhos, utilizou-se e Análise Textual Discursiva, com a criação das seguintes categorias Categoria I: Tendências no uso de plantas medicinais; Categoria II: Contribuições no uso de plantas medicinais e Categoria III: Práticas no uso de plantas medicinais. Estas categorias foram criadas a priori, visando compreender as tendências e práticas envolvendo o uso de plantas medicinais. Pensando na importância da Análise Textual Discursiva, Moraes e Galiazzi (2006) comentam que a Análise Textual Discursiva inicia com a unitarização dos dados em subcategorias, podendo o pesquisador modificar à medida que for analisando os dados.

\section{Resultados e Discussão}

Em relação as teses percebeu-se um quantitativo de 39 pesquisas envolvendo plantas medicinais e que estão presentes na BDTD. No mesmo sentido, pode-se perceber um total de 112 dissertações que se inserem na temática do presente estudo. De modo analítico, pode-se perceber que mais da metade das pesquisas são de dissertações. A Tabela 1 mostra a relação por ano de publicação de teses e dissertações na BDTD.

Tabela 1. Quantitativo de teses e dissertação sobre plantas medicinais presentes na BDTD no período 2015-2020.

\begin{tabular}{lcc}
\hline Ano de publicação & Teses mapeadas & Dissertações mapeadas \\
\hline 2015 & 8 & 29 \\
2016 & 5 & 18 \\
2017 & 14 & 14 \\
2018 & 5 & 29 \\
2019 & 5 & 18 \\
2020 & 2 & 4 \\
\hline Total & 39 & 112 \\
\hline
\end{tabular}

Fonte: Dados da pesquisa (2021). 
Os dados da presente tabela mostram que os anos de 2015 e 2018 foram os que mais tiveram produção na área de plantas medicinais, conforme proposta deste estudo. Pode-se observar que em 2015 teve um total de 37 pesquisas (24,34\%), inserindo teses e dissertações e em 2018 teve um total de 34 (22,37\%). Pode-se afirmar que estes anos, juntos, totalizam $44,71 \%$ das pesquisas desenvolvidas. Da mesma, pode-se inferir que 2020 teve uma baixa produção devido o incentivo das pesquisas na área da saúde, devido a pandemia provocada pelo Novo Coronavírus que atingiu a população global, a partir da segunda metade do ano de 2019.

Pensando nas questões voltadas as Instituições de Ensino Superior (IES) que estão pesquisando esta temática, bem como as regiões brasileiras, pôde-se perceber um total de 51 Instituições de Ensino Superior que estão contribuindo com as pesquisas na área de plantas medicinais. A Tabela 2 mostra o Ranking das universidades e regiões brasileiras que estão publicando suas pesquisas envolvendo as plantas medicinais.

Tabela 2. Relação de instituições por regiões brasileiras, conforme dados da BDTD, 2015-2020.

\begin{tabular}{lll}
\hline Instituições & Aparições & Regiões brasileiras \\
\hline UFPE & 10 & Nordeste \\
UNESP & 9 & Sudeste \\
UFC & 8 & Nordeste \\
UFRPE & 7 & Nordeste \\
UFPA & 6 & Norte \\
UFS & 6 & Nordeste \\
UFSM & 6 & Sul \\
\hline Total & 52 & \\
\hline
\end{tabular}

Fonte: Dados da pesquisa (2021).

Conforme dados, a região Nordeste brasileira é a que mais apresenta pesquisas na área de plantas medicinais, visto que as Instituições: UFPE, UFC e UFS apareceram de forma significativa no banco de dados da BDTD. Isso mostra um incentivo a pesquisa na área de plantas medicinais, podendo ter relação direta com alguma linha de pesquisa em nível de mestrado e doutorado.

Pensando em analisar os trabalhos de dissertações e teses, criou-se três categorias a priori: Categoria I: Tendências no uso de plantas medicinais; Categoria II: Contribuições no uso de plantas medicinais e Categoria III: Práticas no uso de plantas medicinais. Como mecanismo de seleção para classificar os trabalhos analisados utilizou-se tanto os títulos quanto os resumos das pesquisas desenvolvidas e publicadas na BDTD.

\section{Categoria I: Tendências no uso de plantas medicinais}

Se inserem nesta categoria um total de 52,99\% dos trabalhos mapeados e analisados. Conforme estes dados, pode-se dizer que a maioria dos trabalhos se enquadram-na Categoria Tendências no uso de plantas medicinais, discutindo assuntos, como por exemplo, as plantas medicinais no contexto industrial, plantas medicinais nos sistemas médicos locais, sustentabilidade envolvendo plantas medicinais, trabalhos envolvendo plantas medicinais na escola, o uso das TIC's na utilização de plantas medicinais na atenção básica, o uso de extratos de plantas medicinais em casos isolados de cândida. Ainda, há pesquisas sobre o uso de plantas medicinais no tratamento de erisipela, bem como no uso como fototerápicos.

Devido a quantidade de trabalhos mapeados e que se inserem nesta categoria (80 trabalhos), optou-se em discutir os que versam sobre estudos que se relacionam com as tendências no uso de plantas medicinais e suas possíveis reflexões para a 
contemporaneidade. O trabalho de Oliveira Neta (2018), por meio da utilização de plantas medicinais no âmbito agroindustrial, discorre sobre esta crescente tendência mundial, principalmente pelas condições de fitoterapia a partir de compostos bioativos com ações terapêuticas. Segundo a autora, a comercialização destas ervas e subprodutos atende a uma diversidade populacional dentre eles: o consumidor, o feirante, varejistas, mercados e grandes indústrias farmacêuticas/biotecnológicas. Por meio deste estudo pôde-se concluir que as questões fitoterápicas consistem em um mercado promissor que vem ganhando destaque em nível nacional e internacional. Diante disso, as pesquisas etnofarmacológica vem se tornando grande aliada dos centros biotecnológicos de sintetização de medicamentos com informação sobre as ações terapêuticas de determinadas plantas.

A pesquisa de Caetano (2018) discute sobre os estudos etnobiológicos e etnofarmacológicos e a importância de plantas medicinais no uso cultural. Por meio desta investigação, pode-se observar que tem sido medida a popularidade e versatilidade das plantas medicinais. Entretanto, as plantas mais populares são aquelas conhecidas pela maioria das pessoas locais, enquanto as versáteis são as que apresentam o maior número de indicações terapêuticas. Pode-se perceber que este estudo se propôs a testar a percepção local sobre a eficiência, disponibilidade, palatabilidade e o sabor, os quais interferiam na popularidade e na versatilidade no uso de plantas medicinais.

O trabalho de Oliveira (2017) visou discutir a sucessão de culturas em curto período, sendo comum entre os produtores de hortaliças. Nesta perspectiva, observou-se que as espécies em sucessão podem contribuir para a redução de pragas e doenças, bem como pode aumentar a produtividade das culturas, validando os sistemas diversificados. Segundo a autora, após a coleta dos dados de produtividade das culturas, foi realizada a aplicação do índice de eficiência da sucessão das culturas e, logo em seguida, ocorreu a interpretação dos resultados e a validação da eficiência dos sistemas de cultivo com as demais características analisadas.

A investigação de Souza (2018), por meio da utilização de plantas medicinais, abordou que as plantas medicinais são uma prática que perdura há milhares de anos e possui grande relevância na medicina popular. Diante disso, a autora discute que a educação e a conscientização, na obtenção destas plantas, é um elemento primordial, pois o extrativismo de espécies de forma desordenada e o cultivo em áreas com potencial risco de contaminação são fatores que contribuem para o desaparecimento de várias espécies, trazendo desequilíbrio à biodiversidade e prejuízo à saúde humana.

Bomfim (2018) traz provocações relevantes acerca das plantas utilizadas na medicina popular, as quais vêm sendo estudadas devido as suas propriedades terapêuticas. Os estudos deste pesquisador comprovam que a biodiversidade vegetal possui compostos promissores na produção de novos fármacos, principalmente nas espécies vegetais do nordeste brasileiro. A busca por novos agentes terapêuticos eficazes tem se tornado uma alternativa favorável no combate às doenças causadas por fungos, principalmente espécies Candida sp.

O trabalho de Silva (2019) discute que Erisipela é uma infecção que envolve as camadas mais superficiais da pele, sendo causada principalmente por bactérias Gram-positivas como: Streptococcus pyogenes e Staphylococcus aureus. Nesse contexto, o tratamento acontece de forma geral, por meio do uso de penicilinas, entretanto, o uso indiscriminado de antibióticos tem provocado resistência dos microrganismos. Segundo o autor o uso de plantas medicinais entre os pacientes é uma realidade que merece ser vista com atenção, pois o emprego inadequado destas pode piorar as lesões, favorecer o crescimento de microrganismos e aumentar a contaminação.

A pesquisa de Mattos (2015) teve por objetivo investigar o atual perfil de utilização das plantas medicinais e fitoterápicos. Nesse contexto, a credibilidade da fitoterapia como terapia complementar, abrangem o conhecimento e o interesse pelas políticas que regulamentam e incentivam o uso desta prática entre os profissionais que compõe as equipes da Estratégia Saúde da Família (ESF) no município de Blumenau. Para o autor, o estudo mostrou que os profissionais de saúde da ESF de Blumenau são favoráveis à disponibilização das plantas medicinais e fitoterápicos como opção terapêutica aos usuários do Sistema Único de Saúde (SUS), porém, não estão devidamente capacitados para tal e, neste sentido, também externaram seu 
interesse em participar de uma capacitação adequada.

Frente a estes dados, pode-se perceber que as plantas medicinais vem sendo um importante campo de pesquisa científica, contribuindo com novas descobertas e permitindo novas tendências acerca do seu uso. Por meio destes dados, observa-se que há o incentivo no uso de plantas medicinais, visto que a maioria dos trabalhos mapeados se inserem nesta temática.

\section{Categoria II: Contribuições no uso de plantas medicinais}

Se inserem nesta categoria um total de $15,23 \%$ dos trabalhos mapeados e analisados, discutindo questões, como por exemplo, o uso e conservação de plantas medicinais por comunidades quilombolas, o uso de plantas medicinais por diabéticos, os saberes populares e científicos sobre plantas medicinais, o uso de plantas medicinais nativas não madeiráveis, conhecimentos e utilização de plantas medicinais em duas comunidades rurais, o uso de plantas medicinais por pessoas com diabetes mellitus e, ainda, o uso de plantas medicinais por profissionais da saúde.

O trabalho de Pellegrino (2015) discute que as comunidades tradicionais são consideradas detentoras de grande conhecimento sobre a diversidade vegetal e vêm acumulando estes saberes ao longo do tempo, gerando conhecimentos a respeito do ambiente onde estão inseridas. $\mathrm{O}$ estudo teve o objetivo de realizar um levantamento das espécies com potencial medicinal segundo o conhecimento local utilizando duas análises, o Valor de Uso e Fator de Consenso do Informante. Por meio deste estudo, pode-se verificar uma comparação entre homens e mulheres em relação ao conhecimento sobre as plantas medicinais. Da mesma forma, como resultados, percebeu-se que as comunidades tradicionais são importantes lócus da pesquisa científica, principalmente quando se discute contribuições no uso de plantas medicinais.

Fonseca (2018), por meio de uma pesquisa sobre plantas medicinais com pessoas com doenças crônicas como a diabetes, observou que este campo investigativo é profícuo para novas descobertas, principalmente quando se insere no âmbito do serviço prestado pela Estratégia Saúde da Família. Segundo a autora buscou-se investigar acerca desta temática contribuições e reflexões dos gestores e servidores em relação ao uso correto das plantas medicinais, visto que elas contribuem tanto para o desenvolvimento da pesquisa científica, quanto para a saúde e bem-estar dos sujeitos.

O trabalho de Vargas (2017) vem ao encontro da pesquisa de Fonseca (2018), visto que discute os saberes no uso de plantas medicinais em um grupo de usuários de uma unidade de saúde, considerando a autonomia do cuidado na perspectiva da enfermagem assistencial. A investigação buscou conhecer os saberes dos clientes quanto ao uso de plantas medicinais para lançar mão de uma tecnologia educacional, com vistas a autonomia do cuidado em saúde no uso de práticas populares. Por meio dos dados a maioria dos participantes valorizam esse conhecimento e essa forma de tratamento, considerando importante a inserção dela como uma opção de cuidado nos serviços de saúde pública, já que se trata de uma herança cultural.

A pesquisa de Bornancin (2020) teve por objetivo analisar a ocorrência de uma significativa procura por produtos locais e que as práticas de comercialização não estão sujeitas prioritariamente ao preço, mas também à qualidade, à efetividade e ao benefício aportado a saúde. Segundo a autora considerou-se que para a efetiva ativação dos recursos específicos é necessário incorporar nas práticas de comercio dos coletores locais, um conjunto de regulamentações que garantam a segurança à saúde de quem for consumir os Produtos Florestais Não Madeireiros (PFNM) de categoria medicinal para assim ampliar as possibilidades de trabalho e renda das comunidades rurais.

O trabalho de Bueno (2015) afirma que o conhecimento e a utilização de plantas medicinais pelo ser humano é antigo e o acompanha desde os primórdios da civilização. O presente estudo consistiu em uma pesquisa com duas populações rurais a respeito do cultivo, utilização e indicações das plantas medicinais para sintomas e/ou doenças que acometem as famílias. Foram pesquisados 35 agricultores familiares de Santa Albertina (SP) e outros 35 produtores do Assentamento Estrela da Ilha, em Ilha Solteira (SP), por meio de questionário aplicado diretamente nos estabelecimentos rurais. Os dados evidenciam a 
importância do compartilhamento de saberes locais, com vistas a contribuir com o campo científico, principalmente quando se discute plantas medicinais.

A pesquisa de Nayara (2015) relata que o Brasil apresenta elevada prevalência de diabetes e uma longa tradição no uso de plantas medicinais, sendo assim, o estudo teve por objetivo avaliar o perfil de utilização de plantas medicinais e identificou fatores associados ao seu uso, em indivíduos com diabetes mellitus. Os dados na pesquisa confirmaram alta frequência de utilização de plantas medicinais pelos diabéticos no Brasil, sendo recomendado que profissionais de saúde considerem a utilização dessa terapia pelos seus pacientes como uma alternativa no controle desta enfermidade.

Carlini (2018) em sua pesquisa discute a ampliação do "Curso Plantas Medicinais" para "Curso Plantas Medicinais e Fitoterapia" pela Secretaria Municipal do Verde e do Meio Ambiente da Prefeitura de São Paulo. Este curso teve a incumbência de capacitar e sensibilizar profissionais de saúde da Atenção Básica e áreas afins da cidade de São Paulo. Por meio da aplicação deste curso que tinha como intuito o uso da prescrição e a prática fitoterápica pelos profissionais de saúde, pode-se perceber que seu impacto na mudança de comportamento após a capacitação. Tendo como dados do estudo confirmouse a importância da inclusão dos cursos de Plantas Medicinais e Fitoterapia na graduação e na pós-graduação, bem como da capacitação técnica e educação permanente para profissionais de saúde do SUS, sendo uma importante forma de contribuição no uso da temática "'plantas medicinais".

\section{Categoria III: Atividades práticas no uso de plantas medicinais}

Nesta categoria se inserem um total de 15,23\% dos estudos analisados e mapeados, inserindo problemáticas, como por exemplo, avaliação de atividades farmacológicas e toxicidade de plantas medicinais, práticas de cura com plantas medicinais, estratégias e o cuidado da saúde com plantas medicinas, estudo de etnociências nas boas práticas agrícolas de plantas medicinais, conhecimentos e práticas do uso de plantas medicinais com abordagem etnobotânica, práticas socioculturais e proteção do conhecimento tradicional associado ao uso de plantas medicinais, bem como plantas medicinais como recurso didático no ensino de química orgânica.

De forma analítica, o trabalho de Silva (2015) acerca do uso tradicional de algumas espécies como triagem, em associação a aspectos filogenéticos, considera que há comprovações científicas quanto à composição química e atividades farmacológicas. Segundo o autor, a avaliações das atividades antioxidante e hepatoprotetora já realizado em estudos prévios do grupo de pesquisa usando o extrato bruto do Spondias mombin $\times$ S. tuberosa e Turnera ulmifolia Linn. var. elegans, indicaram um efeito terapêutico positivo. Além disso, o estudo traz contribuições acerca da importância de uma avaliação toxicológica em compostos majoritários presentes nos extratos brutos e frações de Licania tomentosa Benth. Fritsch, C. impressa Prance, L. rigida Benth., S. mombim $\times$ S. tuberosa e T. ulmifolia Linn. var. elegans, os quais também podem proporcionar efeitos terapêuticos em atividades antioxidantes e hepatoprotetora.

Guedes (2018) aborda o uso de planta medicinais em mulheres de uma comunidade quilombola de Santa Rita de Barreira, as quais utilizam recursos naturais para prevenir e tratar a saúde de seu grupo. O estudo buscou compreender o uso e a manipulação de plantas para fins medicinais para o tratamento de enfermidades, bem como a transmissão dos saberes relacionados à manipulação desse recurso, as lutas, resistências, construções socioculturais, simbólicas e práticas coletivas de domínio do território pelas mulheres da comunidade. Por meio deste estudo, pode-se perceber que os saberes locais vêm sendo transmitidos pelas mulheres por diversas gerações. Assim, pode-se mencionar as curandeiras e benzedeiras que ao longo dos anos vem ressignificando esses saberes para tratar da saúde do grupo social local.

A pesquisa de Silva (2016) teve por objetivo analisar a produção e o cuidado em saúde através da aplicação da Política Nacional de Práticas Integrativas e Complementares (PNPIC), Plantas Medicinais e Fitoterapia em Estratégia de Saúde da Família (ESF) em Juazeiro/BA, abordando aspectos da transdisciplinaridade que buscam sistematizar o conhecimento da 
complexidade do cuidado em saúde. Os dados da pesquisa apontam a falta de alinhamento conceitual sobre as diretrizes da PNPIC e produção do cuidado com oferta de produtos relacionados à fitoterapia na ESF. No entanto, conclui-se que o conhecimento da PNPIC no território da ESF, tanto na esfera gerencial, como nas relações de produção do cuidado é relevante para a sua efetivação destas políticas.

Veltri (2017) relata em sua pesquisa que o uso das plantas medicinais aromáticas e condimentares pela humanidade vem sendo utilizado desde os tempos mais remotos. A pesquisa revela também a associação existente entre o conhecimento empírico e o conhecimento científico, bem como sua importância para diferentes setores da sociedade. Segundo a autora à crescente abrangência e demanda do mercado em relação ao uso de plantas medicinais, tornam-se maiores as necessidades de investimentos para a produção contínua da matéria-prima, a fim de atender às diferentes áreas de interesse. Diante disso os dados analisados revelam não só o potencial produtivo dos agricultores, mas também as fragilidades encontradas por eles, no campo e, também, nos âmbitos socioeconômicos. A complexidade das relações humanas entre diferentes atores sociais que surge nos relatos acaba refletindo na cadeia produtiva do grupo de plantas estudado.

Alves (2016) aborda os conhecimentos e tratamentos estabelecidos pela Medicina Científica, que são hegemônicos no Sistema de Saúde Pública e sobrevivem na memória do povo, nas concepções, crenças e costumes que compõem a Medicina Popular. Na visão do pesquisador, os conhecimentos tradicionais sobre tratamentos com plantas são utilizados desde o início da humanidade e acabam passando de geração em geração por meio da transmissão oral e familiar. Da mesma forma, o tratamento das doenças constitui hoje um interessante aspecto de nossa cultura, levando em consideração a historicidade das práticas que o compõem.

A pesquisa de Teixeira (2017) objetivou analisar as formas de proteção dos conhecimentos tradicionais presentes nas práticas socioculturais no uso e manejo de plantas medicinais em comunidades tradicionais da Amazônia. Segundo a autora, as práticas no uso e manejo de plantas medicinais na Amazônia estão presentes no complexo contexto sociocultural dos povos tradicionais. Eles são detentores de um conhecimento tradicional associado aos recursos naturais da região, os quais, historicamente, têm estabelecido uma forma de relação simbiótica com a natureza, pautada nos princípios da sustentabilidade para conservação socioambiental e cultura.

A investigação de Maia (2019) apresenta uma temática transdisciplinar voltada a Plantas medicinais, bem como, na forma de uma proposta contextualizada, visando contribuir para uma aprendizagem significativa no ensino de Química Orgânica, bem como à formação integral do estudante e, não somente, para o desenvolvimento cognitivo. O estudo foi realizado no Instituto Federal de Educação, Ciência e Tecnologia do Ceará (IFCE) da cidade de Sobral - CE, tendo como público-alvo, estudantes do curso de Tecnologia de Alimentos. Como atividades, foram realizados momentos complementares e experimentais, na forma de aula de campo e oficinas que foram oferecidas aos alunos, com vistas alcançar uma aprendizagem significativa. Para a autora o trabalho permitiu contextualizar o ensino de Química Orgânica a partir de experiências de vida que foram além dos limites físicos da sala de aula e culminou com relevantes informações compiladas no produto educacional intitulado "Cartilha de plantas medicinais: sabedoria popular e conhecimento científico para o ensino das funções orgânicas". Atividades como esta são fundamentais no campo educacional, visando inserir momentos práticos e reflexivos no cotidiano dos alunos.

\section{Conclusão}

Por meio do presente estudo pode-se observar as diferentes contribuições, atividades e tendências no uso de plantas medicinais, bem como seus possíveis reflexos no campo sociocientífico. As plantas medicinais, desde os primórdios das civilizações vem sendo utilizadas no combate e controle de enfermidades que acompanham o processo evolutivo do homem. Seu uso, muitas vezes, é oriundo dos saberes tradicionais, os quais são identitários de um determinado grupo social. 
Por meio desta investigação, pôde-se perceber que a região nordeste brasileira vem intensificando as pesquisas nesta área, contribuindo com o processo de divulgação e sustentação da ciência. As plantas medicinais se constituem de uma importante temática, visto que insere saberes locais, conhecimentos na área da saúde, no campo social, ambiental, cultural e econômico. Nesta perspectiva, pode-se dizer que é uma temática que necessita de constantes pesquisas, elucidando os diferentes potenciais terapêuticos de diferentes espécies vegetais.

Como este estudo teve metodologia essencialmente bibliográfica e, ainda, utilizou-se apenas uma base de dados (BDTD), sugere-se novas investigações em outras bases de dados, como por exemplo, IBICT, Scielo e periódicos qualificados, visando um mapeamento e divulgação das diferentes pesquisas envolvendo plantas medicinais e que estão sendo desenvolvidas no Brasil e publicadas nos meios científicos.

\section{Agradecimentos}

Agradeço a oportunidade de ter participado como bolsista do Projeto de Pesquisa "Plantas medicinais utilizadas pelas mulheres da Comunidade de São João do Barro Preto do Município de Júlio de Castilhos, Rio Grande do Sul, Brasil”, o qual está vinculado ao Instituto Federal Farroupilha - Campus Júlio de Castilhos. Agradeço também as demais integrantes deste projeto pelos compartilhamentos de saberes, vivências e experiências.

\section{Referências}

Alves, H. K. D. R. (2016). Conhecimentos e práticas do uso de plantas medicinais com Abordagem etnobotânica, no município de Morrinhos-Goiás: estudo de caso. 2016. 109 f. Dissertação (Programa de Pós-Graduação stricto sensu em Ambiente e Sociedade). Universidade Estadual de Goiás, Câmpus Morrinhos, Morrinhos.

Araújo, M. M. (2009). Estudo etnobotânico das plantas utilizadas como medicinais no assentamento Santo Antônio, Cajazeiras, PB, Brasil. 2009. 130 f. Dissertação (Mestrado - Centro de Saúde e Tecnologia Rural). Universidade Federal de Campina Grande, Campina Grande.

Bomfim, F. dos S. (2018). Avaliação do potencial antifúngico de extratos de plantas medicinais frente a isolados clínicos de Candida. 2018.75 f. Tese (Programa de Pós-Graduação em Inovação Terapêutica). Universidade Federal de Pernambuco Centro de Biociências, Recife.

Bormancin, A. P. A. de. (2020). O uso das plantas medicinais nativas não madeiráveis: possibilidades de um recurso específico potencial no litoral do Paraná. 2020. 108 f. Dissertação (Curso de Pós-Graduação em Desenvolvimento Territorial Sustentável). Universidade Federal do Paraná, Matinhos.

Bragança, L. A. R. D. (1996). Plantas medicinais antidiabéticas: uma abordagem multidisciplinar. Rio de Janeiro: Editora da Universidade Federal Fluminense.

Bueno, A. R. (2016). Conhecimento e formas de utilização de plantas medicinais em duas comunidades rurais: Agricultores familiares de Santa Albertina (SP) e assentados de ilha solteira (SP). 2016. 102 f. Dissertação (Programa de Pós-Graduação em Agronomia) Faculdade de Engenharia - UNESP - Campus de Ilha Solteira, Ilha Solteira.

Catetano, R. A. (2018). Como as pessoas selecionam plantas medicinais em sistemas médicos locais? 2018.56 f. Dissertação (Programa de Pós-Graduação em Botânica). Universidade Federal Rural Pernambuco, Recife.

Fonseca, F. F. (2018). O uso de plantas medicinais por diabéticos acompanhados pela estratégia saúde família. 2018.105 f. Dissertação (Programa de PósGraduação em Ensino em Saúde). Universidade Federal dos Vales do Jequitinhonha e Mucuri, Diamantina.

Gil, A. C. (2002). Como elaborar projetos de pesquisa. Atlas.

Gill, L. A. (2009). Trajetória de benzedores negros ao sul do Brasil. Mestrado em História e Sociologia.

Gomes, M. J. M. (2002). Ambiente e pulmão. Jornal Brasileiro de Pneumologia, 28, 261-269.

Guedes, A. C. B. (2018). Mulheres quilombolas e uso de plantas medicinais: práticas de cura em Santa Rita de Barreira/PA. 2018. 199 f. Dissertação (Programa de Pós-Graduação em Desenvolvimento Sustentável do Trópico Úmido do Núcleo de Altos Estudos da Amazônia). Universidade Federal do Pará, Belém.

Haraguchi, L. M. M. (2018). A fitoterapia praticada por profissionais de saúde participantes do curso "Plantas Medicinais e Fitoterapia" realizado pela Secretaria Municipal do Verde e do Meio Ambiente de São Paulo (2014/2015). 2018. 113 f. Dissertação (Programa de Pós-Graduação em Saúde Coletiva). Universidade Federal de São Paulo, Escola Paulista de Medicina, São Paulo.

Maia, Z. C. (2019). Plantas medicinais como recurso didático no ensino de química orgânica. 2019. 66 f. Dissertação (Programa de Pós-Graduação em Ensino de Ciências e Matemática). Universidade Federal do Ceará, Centro de Ciências, Fortaleza. 
Mattos, G. (2018). Utilização das plantas medicinais e fitoterápicos na atenção primária em saúde: a visão dos profissionais de Blumenau. 2015. 75. f. Dissertação (Pós-Graduação em Saúde Coletiva do Centro de Ciências da Saúde). Universidade Regional de Blumenau, Blumenau.

Moraes, R.; GALIAZZI, M. do C. (2006). Análise Textual Discursiva: processo reconstrutivo de múltiplas faces. Ciência \& Educação. 12(1), 117-128.

Nayara, C. B. (2015). Perfil de utilização e fatores associados ao uso de plantas medicinais em pessoas com diabetes Mellitus em Minas Gerais, Brasil. 2015. 100 f. Dissertação (Programa de Pós-graduação em Medicamentos e Assistência Farmacêutica). Faculdade de Farmácia da Universidade Federal de Minas Gerais, Belo Horizonte.

Nery, V. C. A. (2006). Rezas, Crenças, Simpatias e Benzeções: costumes e tradições do ritual de cura pela fé. In: Anais do XXIX Congresso Brasileiro de Ciências da Comunicação (INTERCOM). Universidade de Brasília- GO, Brasília.

Nobrega, J. Y. de L. (2017). Estudo etnobotânico de plantas medicinais utilizadas em rezas e benzeduras em município do Sertão Paraibano. 2017.45 f. Dissertação (Programa de Pós-Graduação em Sistemas Agroindustriais PPGSA). Universidade Federal de Campina Grande, Pombal.

Oliveira Neta, F. B. de. (2018). As plantas medicinais no contexto agroindustrial. 2018. 23 f. Dissertação (Programa de Pós-graduação em Sistemas Agroindustriais, Modalidade Profissional). Universidade Federal de Campina Grande, Pombal.

Oliveira, S. G. de. (2017). Sustentabilidade de sistemas de produção em sucessão entre hortaliças e plantas medicinais. 2017. 50 f. Tese (Pós-Graduação em Agronomia). Faculdade de Ciências Agronômicas da UNESP, Botucatu.

Pellegrino, N. S. L. (2015). Uso de plantas medicinais nas comunidades quilombolas de Coremas, Paraíba-PB, Brasil. 2015. 60 f. Dissertação (Programa de Pós-Graduação em Desenvolvimento em Meio Ambiente). Universidade Federal da Paraíba, Coremas Paraíba.

Rahman, A; KANG, S. C. (2009). Inhibition of foodborne pathogens and spoiling bacteria by essential oil and extracts of Erigeron ramosus (walt.) b.s.p. Journal of Food Safety, 29, 176-189.

Rudder, M. C. (2002). Guia compacto das plantas medicinais. Rideel.

Silva, A. F. da. (2018). Desenvolvimento de uma solução irrigadora de canais radiculares utilizando o extrato de plantas medicinais do semiárido. 2018.73 f. Dissertação (Programa de Pós-Graduação em Odontologia). Universidade Estadual da Paraíba, Campina Grande.

Silva, G. A. da. (2015). Avaliação de atividades farmacológicas e toxicidade de plantas medicinais do semiárido do Nordeste brasileiro. 2015 . 182 f. Tese (Programa de Pós-Graduação em Desenvolvimento e Inovação Tecnológica em Medicamentos) Universidade Federal do Rio Grande do Norte, Natal, 2015.

Silva, A. A. da. Conhecimento e crenças sobre o uso de plantas medicinais no tratamento das cefaleias. 2015. 115 f. Dissertação (Programa de Pós-graduação em Neuropsiquiatria e Ciências do Comportamento, com área de concentração em Neuropsicopatologia). Universidade Federal de Pernambuco, Recife.

Souza, V. K. S. de. (2018). Tecnologia de informação e comunicação como ferramenta auxiliar na utilização de plantas medicinais na atenção básica. 2018. Dissertação (Programa de Pós-Graduação em Saúde Humana e Meio Ambiente). Universidade Federal de Pernambuco.

Teixeira, N. A. (2017). Práticas socioculturais e proteção do conhecimento tradicional associado ao uso de plantas medicinais em Caapiranga/AM. 2017. 135 f. Dissertação (Programa de Pós-graduação em Serviço Social e Sustentabilidade na Amazônia). Universidade Federal do Amazonas, Manaus.

Vargas, E. C. A. de. (2017). Interface entre os saberes populares e científicos sobre plantas medicinais: perspectiva da autonomia do cuidado em saúde. 2017. 83 f. Dissertação (Programa de Pós-Graduação Stricto Sensu - Mestrado Profissional em Enfermagem Assistencial Escola de Enfermagem). Universidade Federal Fluminense, Niterói.

Veltri, A. L. A. (2017). Estudo de etnociências nas boas práticas agrícolas de plantas medicinais, aromáticas e condimentares do município de Botucatu, SP. 2017. 112 f. Dissertação (Pós-Graduação em Agronomia). Faculdade de Ciências Agronômicas (FCA), Botucatu. 